\title{
NARRATIVA PERSONAL, TRAYECTORIA DE VIDA Y CONSTRUCCIÓN DE IDENTIDADES
}

Mirta Ana Barbieri

\section{Resumen}

Al plantearse la investigación social, y utilizarse el instrumento de la entrevista como proceso comunicativo (re-conocimiento), los sujetos que narran reconstruyen sus itinerarios. Los relatos de vida ponen en evidencia la trama social a través de lo particular, permitiendo asomarse a una diversidad de espacios complejos donde dialogan y/o se producen los cambios intergeneracionales.

Los interlocutores develan sus experiencias, algunas íntimas, poniendo de manifiesto aquellas familiares, sociales, conectando con valores y modelos.

La situación de encuentro, en la que el investigador se ve involucrado, es una fuente de conocimiento útil, una instancia oportuna para la reflexión sobre la intersubjetividad a la que se enfrenta. Estos son algunas de las preocupaciones teóricas y metodológicas abordadas en el ensayo.

Palabras clave: Narrativa, sujetos, relatos, identidad, trama social.

\section{Abstract.}

To consider social research by using interviews tools as a communicative process (re-cognition), those who relate rebuilt their itinerary. Life history that gives evidence of the social weft through private, allowing to see the diverse and complex space where intergenerational changes are produced.

Interlocutors show their experiences, some intimates highlighting families, socials, related with values and patterns.

The encounter situation, in which the researcher is involved, is a source of useful knowledge, is an opportunity to analyze the intersubjetividad faced. These are some of the theoretical and methodological concerns addressed in this paper.

Keywords: narrative, narration, identity, life history.

\section{La narrativa personal}

En la investigación social, el enfoque metodológico basado en la utilización de testimonios de vida, nos aproxima -desde la subjetividad relatada-, a la apropiación de lo social, a las maneras en que los sujetos conforman sus identidades en concordancia o en desacuerdo con los valores sociales más generalizados. La narrativa personal posibilita comprender las distintas modalidades según las cuales los sujetos significan el mundo, dan cuenta de sus trayectorias y proyectos de vida y de sus adscripciones generacionales, de género, de clase, étnicas.

En la recuperación de las experiencias de una vida, el itinerario personal se conjuga con el de otros, en tantos miembros de una familia, una comunidad, un colectivo generacional, como emergentes de un complejo entramado histórico, social y cultural. Ese marco de referencia hace posible un análisis e interpretación más comprensiva del material biográfico que los sujetos actualizan en su narrativa. 
La percepción de quienes somos ahora, quienes fuimos y en quien nos queremos convertir, suele estar fragmentada. Al narrar la propia historia en términos de consistencia y de cambio a la vez, intentamos ser reconocidos como la misma persona que hemos sido siempre, al mismo tiempo que una persona distinta. (Portelli: 1993).

La memoria gira en torno de la relación pasado y presente e involucra un proceso selectivo y continuo de reconstrucción y transformación de experiencias evocadas. Las modificaciones en la percepción del pasado revelan el esfuerzo del narrador por buscarle un sentido. Las historias relatadas no son representaciones exactas de lo acontecido y vivido, sino que se amoldan para que se ajusten y se logre una mayor consonancia entre las identidades del pasado y el presente. El ejercicio narrativo es terapéutico; y el encuentro un espacio propicio para sacar a luz, y reconciliarse con un pasado con el cual sea posible convivir (A. Thompsom: 1997).

Las vidas se relatan en relación a puntos de partida y de ruptura, en términos de continuación, desarrollo y/o desencuentro con otras trayectorias y valores, con expectativas y mandatos familiares $y$ sociales. Los testimonios dan cuenta de que los itinerarios de vida no son lineales, conformados de acuerdo a modelos previsibles, sino que en la mayoría de los casos presentan una gran complejidad. Pero en unos y otros casos los discursos muestran que los sujetos son hijos o exponentes de su época, al mismo tiempo que enuncian lo particular y distintivo de sus vidas.

Durante el relato hay una selección del material; proceder que tiene que ver con una decisión del narrador, más o menos espontánea, pero también implica negociaciones más o menos implícitas con el entrevistador, quien estimula que la información vaya en determinada dirección. Las condiciones de sexo, edad, personalidad, ideología del entrevistador, así como el raport logrado en la situación de encuentro, influyen en el tipo del material que surge en la entrevista.

Apelando a su memoria, el narrador reactualiza las identidades a las que adscribe, recuperando modalidades según las cuales ha maniobrado frente a las interpelaciones de su época, desafiando roles y modelos establecidos, o bien señalando cómo los ha re significado, apropiado o transformado. Las experiencias vividas son procesadas a través de su singularidad, a la vez que los mundos de significación son conformados en virtud de las múltiples pertenencias sociales. La narrativa pone de manifiesto que las identidades, lejos de ser consolidadas son móviles, cambiantes, así como los procesos de socialización, que son constantes y pueden operar también en cuanto a modelar el relato. La tarea del investigador implica descubrir los discursos sociales, culturales, institucionales, en los que se inscribe el relato de sus interlocutores.

\section{La impronta generacional}

¿Cómo es la mirada hacia el pasado? ¿Qué recuperan las narrativas que hablan de las diversas maneras en que los sujetos han debido afrontar los desafíos del diario vivir? En los relatos de vida de las personas mayores es posible recomponer imágenes de una trama social que, de otra manera se perdería para siempre; es asomarse a la matriz de las identidades múltiples que nos conforman, a los proyectos de vida de los que fueron jóvenes tiempo atrás. Esa recuperación, tiene también la virtud de restaurar la identidad del que narra, quien a través de un ejercicio reflexivo se posiciona como protagonista y/o testigo de múltiples acontecimientos, de transformaciones sociales, política, tecnológica y familiares.

La revisión retrospectiva por lo general asume la forma de un balance de vida, que clasifica desde el presente, logros y fracasos. Al relatar, se suele expresar la pertenencia a un grupo 
generacional, un colectivo a partir del cual las experiencias del pasado son evaluadas en términos de transgresión o adaptación a los valores y modelos más generalizados, y de anticipación y transmisión a las nuevas generaciones, marcando puntos de encuentro y de quiebre entre lo recibido y lo legado.

Los relatos biográficos pueden identificar el espíritu de una generación encarnado en aquellos que compartieron un determinado contexto témporo-espacial, que conformaron un segmento social particular y fueron marcados por una socialización en valores que han implicado un punto de ruptura con modelos y valores anteriores (la generación del mayo francés del '68, los hippies y los militantes de los setenta, entre las más reconocidas y próximas en el tiempo) ${ }^{1}$.

La recuperación del pasado puede tener un sentido ejemplificador: "en mi época había más respeto por los mayores"... "la madre siempre estaba en la casa", señala una interlocutora de mayor edad, idealizando valores generalizados en su juventud, sobre la familia, las relaciones intergeneracionales, basados en jerarquías de género y edad, y una adscripción de la mujer a roles domésticos, que hoy han perdido vigencia. (Barbieri: 2008).

No siempre la evocación del tiempo transcurrido es nostálgica, es posible que al confrontarlo con el presente los mayores reconozcan que las generaciones más jóvenes han producido cambios favorables. ${ }^{2} \mathrm{Al}$ comparar su generación con la de sus hijas, MIRIAM señala, en relación al proyecto de vida personal: "Nosotros es como que primero lo vivimos y después lo elaboramos, ellas lo tienen más teorizado" (...) destaca la mayor posibilidad de elección actual de las jóvenes: "de verse a sí mismas, de ver qué es lo que quieren" (...), "son conscientes de que deberán hacer sus elecciones de vida y para ello se sienten más libres y mejor preparadas". Su reflexión da cuenta de cómo se registra el proceso de transformación de modelos y valores que opera a través de las generaciones. (Barbieri: 2008)

En las historias que los jóvenes relatan, contrariamente a la que cuentan los mayores, pasa a un primer plano la reflexión sobre el propio proyecto y el porvenir, puesto que el tiempo futuro supera lo ya vivido.

\section{Trayectoria personal y familiar}

He señalado que la historia personal se enlaza con la familiar, las trayectorias individuales se modelan continuando o transformando los itinerarios familiares. Numerosas investigaciones empíricas destacan el valor de los procedimientos biográficos para analizar el rol de los individuos y las familias en procesos de transmisión intergeneracional y en relación al cambio social. ${ }^{3}$

Bertaux y Bertaux Wiame (1993) hacen referencia al micro-clima familiar: ese universo simbólico-cultural que orienta la acción y las interacciones de sus miembros. Allí está la clave de los valores, expectativas, creencias, roles asignados y sistemas de premios y castigos compartidos.

Las familias ocupan un lugar en un espacio social multidimensional $y$ en virtud de

1 Bovone (1989) destaca el valor metodológico de los testimonios biográficos en su investigación sobre intelectuales italianos que habían protagonizado la movilización estudiantil del '68. Socializados en valores de igualdad, solidaridad, compromiso político, construyeron identidades complejas y abiertas, articulando las tendencias innovadoras con los anteriores valores sociales y familiares.

2 Las mujeres de generaciones mayores y de edad intermedia que entrevisté, al comparar con sus experiencias, reconocían como un logro de la generación de sus hijas la vigencia de relaciones de género más igualitarias (Barbieri: 2008).

3 La transmisión familiar tiene como propósito fundamental la trascendencia intergeneracional (P. Thompsom: 1993). Las familias proporcionan a sus miembros un variado capital de recursos de diversa índole: materiales, simbólicos, culturales, financieros, de servicios, redes. La apropiación del mismo es contradictoria: puede contribuir al desarrollo personal de los sujetos, pero también limitarlo, es positiva en tanto la joven generación pueda darle un sentido de descubrimiento personal, (Bertaux-Wiame: 1993). Sobre las trayectorias femeninas véase Borderias: 1991, Barbieri: 2000, 2008. 
su posición en él, sus miembros tienen mayores o menores posibilidades de acceder a diversos tipos de recursos. Estos variados bienes pueden ser objeto de transmisión a los descendientes. A veces los hijos están dispuestos a "heredar" el legado familiar, continuar el camino trazado por sus mayores. En otros casos los intereses y perspectivas de los hijos no coinciden con los paternos.

El seguimiento de las trayectorias vitales, -entendidas como el conjunto de movimientos sucesivos de un agente dentro de un espacio estructurado-, hace posible conocer qué logros se obtuvieron y cuáles fueron los fracasos. En qué medida proyectos que en algún momento se previeron como posibles: una carrera, un viaje, emprendimiento, casarse, emigrar, pudieron ser alcanzados o no. Documentar los fracasos pone en evidencia los límites del campo de posibilidades de cada familia. (Bertaux: 1994, González: 1995)

La situación de la familia en el espacio social hará más o menos factible su acceso a bienes y recursos de distinta índole. Es de fundamental importancia considerar el contexto social dentro del que se desarrollan las estrategias de vida de los individuos y las familias, en los que se conocen y se evalúan las oportunidades, tienen lugar las transmisiones, se forman las trayectorias y se juegan los destinos diversos o similares de una red familiar. En este marco, el tiempo histórico afecta e influye sobre el tiempo familiar e individual existencial, se marcan los cursos y derroteros de las vidas. (González: 1995)

La entrevista biográfica es un espacio propicio para hacer un balance entre lo que ha sido de nuestra vida y lo que esperamos de ella. Se expresa en términos de satisfacción e insatisfacción. La familia aparece como primer grupo de referencia, en tanto institución socializadora, primaria y transmisora. Muchas veces, al revisar la historia familiar, las demandas responsabilizan a los padres por no haber fomentado el acceso a una mayor escolaridad, al mundo laboral, o permitido hacer elecciones de vida más libres. Las experiencias de socialización para algunas mujeres han resultado desventajosas en comparación con las de los hermanos varones. Pero según los relatos aquí registrados, se perciben cambios en los itinerarios que las mujeres refieren, en relación a los de sus madres y abuelas, socializadas en un contexto en el que el imaginario acerca del trabajo y la familia era otro. (Barbieri: 2008)

Cabe destacar, que la influencia de los padres en la construcción de las identidades $\mathrm{y}$ trayectorias familiares, escolares $\mathrm{y}$ laborales, ha disminuido en las últimas décadas. El grupo de los pares, otras instituciones, múltiples experiencias de vida, cotidianamente contribuyen a modelar y redefinir identidades e itinerarios. En particular en las nuevas generaciones, se aprecia un gran salto en relación a los antecesores, sobre todo en los casos en que los recursos familiares de carácter material, social y simbólico no son de utilidad para afrontar los desafíos que el contexto impone a los más jóvenes.

Cabe señalar que los vertiginosos cambios sociopolíticos vinculados a los procesos de modernización y urbanización, acelerados después de la mitad del siglo veinte, implicaron entre otras cuestiones, transformaciones en la cotidianidad de las familias, en la conformación de la trayectoria de vida de los sujetos, marcando un quiebre con ese devenir del curso de vida que implicaba un desarrollo más o menos previsible de ciclos de capacitación, trabajo, consolidación de una familia, dando paso a la construcción de identidades más abiertas, complejas y fluidas. Concomitantemente, el creciente acceso femenino a la escolarización y al mundo laboral, fue liberador pero también resultó particularmente conflictivo para las mujeres; requirió una reacomodación de los roles familiares, abriendo nuevas miradas 
sobre la feminidad y la masculinidad, la maternidad y la paternidad, los roles y proyectos personales.

\section{Género, identidad y narrativas}

Durante varios años he registrado relatos de vida de hombres y mujeres que expresaron las particulares maneras en que los interlocutores maniobran con las vicisitudes del diario vivir. Los testimonios ponen de manifiesto los mundos sociales a través de los cuales los sujetos reconstruyen su identidad, priorizan dimensiones del ámbito privado, del mundo de los afectos o del trabajo, la militancia, la esfera pública.

Por lo general, en sus narrativas las mujeres tienden a expresar su identificación principal con la vida familiar y privada, mientras los hombres jerarquizan el mundo del trabajo y de la esfera social y pública. Pero hay excepciones en ambos casos. ${ }^{4}$

La referencia a las emocionesy la vida personal es más común en los relatos femeninos. Las versiones de las mujeres generalmente son más detallistas y descriptivas. Ellas están más predispuestas a revelar cuestiones íntimas, evocar con mayor precisión acontecimientos familiares (vinculadas al parentesco, casamientos, nacimientos, enfermedades, muertes, ocupaciones, mudanzas y otros hechos del pasado familiar). Los hombres son más reacios a hablar de sí mismos y tienden a referir sus vidas principalmente en términos de sus experiencias laborales.

En la investigación en la que registré narrativas femeninas, interesada en recuperar procesos de construcción de la identidad de género, según las versiones de mujeres de diferentes edades y clase social, residentes en Buenos Aires, la inscripción de clase remitía a modalidades de vida compartidas, mientras que la pertenencia generacional ejemplificaba distintos momentos del ciclo vital (Barbieri: 2008). Si bien en parte evidenciaban ser concordantes con modelos y expectativas propias de cada época, también dieron cuenta en los distintos casos, de variaciones en prácticas y representaciones, señalando cómo las mujeres impugnaban construcciones culturales generalizadas.

Me interesó recuperar en los relatos, no solo regularidades y consensos, sino también contradicciones, conflictos y ambivalencias. Las versiones de las mujeres entrevistadas expresaron núcleos conflictivos que señalaban desafíos no resueltos, mostraban la complejidad de las identidades que ellas ponían en juego. ${ }^{5}$

En las mujeres de mayor edad que entrevisté, los testimonios no impugnaron la adscripción doméstica femenina, principal espacio de identificación recibido de sus progenitoras. Es en el caso de las generaciones intermedias,- las mujeres que a partir de las décadas del sesenta y setenta del siglo veinte, accedieron a espacios laborales y educativos y lograron trascender los ámbitos de identificación materna, -que en sus discursos particularmente reflexivos documentan la tensión cruzada entre lo personal y lo familiar, así como la búsqueda un proyecto que trascienda el mundo doméstico y privado.

4 En "Un artista itinerante" (Barbieri: 1992) el narrador centraliza su discurso en sus afectos y emociones a pesar de mis intentos de recabar información sobre sus opiniones y perspectivas acerca del contexto social más amplio. Inversamente en los relatos registrados por Briones (1992) "De meta-relatos e identidades", y Smolensky (1992) "Una mujer italoargentina", ambas entrevistadas retacean hablar de su vida familiar, prestigiando en el primer caso las referencias al exitoso desempeño profesional y en el segundo dando cuenta de sus identidades étnicas, de clase y de género, y reflexionando sobre la realidad sociopolítica del país.

5 Los testimonios de mujeres de clase media, de generaciones intermedias, aparecían teñidos por la ambivalencia y ambigüedad, expresaban la dificultad de resolver satisfactoriamente las exigencias de la doble demanda, de conciliar responsabilidades familiares y proyecto personal. En el caso de las mujeres del sector popular los discursos también señalaron conflictos particulares. Reflejaban percepciones de sí mismas como débiles y fuertes al mismo tiempo, que resultaban contradictorias con sus reales prácticas de vida, que las mostraban como agentes activas en la búsqueda de alternativas para superar las condiciones estructurales de inequidad y escasez de oportunidades. 
El cambio fundamental en la construcción de la identidad de género, se hará evidente en los testimonios de la generación de mujeres más jóvenes, quienes ya se han apropiado de las conquistas de sus antecesoras: el acceso al mundo de la educación y el trabajo. Ellas deberán luchar por preservar y desarrollar el propio proyecto y seguir bregando por una redistribución más equitativa de las responsabilidades domésticas y familiares.

Las transformaciones generacionales implican que las mujeres no se adscriben al rol doméstico de sus madres. La experiencia de escolarización más prolongada, contribuye a revalorizar la percepción que ellas tienen de sí mismas, es un incentivo para que luchen por incorporarse al mundo del trabajo, en actividades ligadas a la aplicación de los entrenamientos y capacitaciones adquiridas.

$\mathrm{Al}$ priorizar la vida laboral y profesional, las jóvenes retrasan el proyecto de constitución de una familia y la maternidad. Una de las modificaciones más importantes en las relaciones de género, entre jóvenes pertenecientes al sector medio, es el aumento de las uniones consensuales. Se ha re significado la cohabitación, que en épocas anteriores era estigmatizada. ${ }^{6}$ Las mujeres optan por tener menos hijos o ninguno, por cohabitar con su pareja o vivir en soledad.

\section{Identidad colectiva y alteridad}

La presentación unitaria del sujeto conlleva al mismo tiempo la coexistencia de variadas subjetividades y pertenencias, que demarcan diferencias entre diversos campos de propios y extraños. Mientras la identidad personal se refiere al proyecto o itinerario de vida individual (lo que hace distintivo de los otros), la social incluye el individuo en tanto miembro de un determinado grupo nacional, religioso, étnico, lingüístico. ${ }^{7}$

La inclusión da pertenencia, contención, raíces, reivindica la particularidad y conforma un nosotros. La identidad se construye y se reconstruye constantemente en el seno de los intercambios sociales. Identidad y alteridad están indisolublemente vinculadas en una relación dialéctica en la que la identificación es la contrapartida de la diferenciación.

El espacio de la entrevista biográfica es propicio para redefinir adscripciones identitarias y marcar la alteridad, recuperar diferencias y delimitar fronteras, territorios del nosotros y los otros. Atravesar esa experiencia impacta en la subjetividad y en las identidades del investigador y es fuente propicia para una cuidadosa reflexión.

Ruth Behar (2006) en la historia de vida de ESPERANZA, señala su interés por indagar en la particular relación: "qué unió a una vendedora ambulante mexicana y a una antropóloga cubano-americana"; dos mujeres que provienen de mundos diferentes. La experiencia la lleva "a pensar seriamente en qué América era mi América y en qué soy yo como mujer que cruza las fronteras como manera de buscarse la vida". (...) Más adelante, Behar expresa que finalizando el trabajo de este libro, inició "una serie de intensos viajes de regreso a Cuba, que todavía hago, en busca de recuerdos, de identidad, de un hogar.

Behar creyó importante documentar "la angustia que sentí con respecto al poder

6 Ha perdido peso la celebración del contrato de orden civil y/o religioso. Si bien el prestigio de la maternidad no ha desaparecido, ésta y el matrimonio han dejado de ser las principales metas femeninas. A esta transformación ha contribuido la mayor autonomía y capacidad de autoabastecerse de las jóvenes. (Barbieri:2008)

7 La pretensión homogeneizante que caracteriza en el presente a la globalización se confronta con la heterogeneidad del multiculturalismo. En los territorios nacionales los colectivos religiosos, étnicos, lingüísticos, culturales, reclaman el reconocimiento de su identidad, diferencia y particularidad. En una realidad interesada en masificar se reivindica el derecho a tener un lugar en el mundo. Ambos fenómenos actualizan el tema de la identidad personal (quién soy y quién quiero ser) y social (quiénes somos y quiénes queremos ser). 
que tuve para transportar la historia de ESPERANZA a través de la frontera" (...) "Se supone que los antropólogos no hablen de su vida, para no oscurecer su concentración en "el otro"... Mientras trataba de hacerlo, "me vi forzada a hacerme preguntas esenciales. ¿Por qué existe una frontera entre los Estados Unidos y México? ¿Por qué yo la puedo cruzar fácilmente y ESPERANZA no?" (Behar: 2006, 30-31).

Las diferencias se construyen en las interacciones cara a cara. Durante el encuentro el investigador puede resultar incluido en el juego de construir la alteridad. Sobre esto, un texto de Portelli (1992), me parece oportuno mencionarlo. Cuando registra la historia de vida de un ex minero de Kentucky (Norteamérica), el autor entrevista también a su esposa. La mujer evoca un pasado familiar esclavo, las experiencias de discriminación profunda que habían sufrido sus antepasados; actualiza ese dolor ancestral. La desigualdad no resuelta entre negros y blancos.

Siempre habrá una línea, -dice Portelli-, en la que convergen temas cruciales, siendo en esa ocasión, la discriminación racial. La interlocutora instala una división que demarca dos espacios que los separan, en tanto él es un entrevistador blanco. "No confío en usted" - le dice la mujer- . En su memoria afloran las raíces profundas del sentimiento hacia los blancos, y citando palabras de su abuela continúa:"... no importa lo bueno que parezcan ser, lo bien que hablen..., serás siempre negra" (Portelli: 1992, 11-12).

El autor reitera que siempre habrá una línea divisoria. Con sus palabras, la entrevistada la trazó y al declarar su imposibilidad de atravesarla, ya estaba hablando del otro lado de frontera.

El narrador en otros casos, procura construir la diferencia y a los otros en un intento de restaurar su identidad. Marca la alteridad instalándola en un polo desvalorizado de una dicotomía que señala una dualidad irreductible que con frecuencia ha sido utilizada para oponer extranjeros versus nativos, lo urbano/lo rural, ciudad/interior, blancos/negros.

Me resulta muy sugerente referir brevemente un caso ilustrativo: es el relato de vida de una mujer argentina, descendiente y perteneciente a una colectividad de colonos autodenominados alemanes del VOLGA, quienes tienen un asentamiento centenario en el país (Argentina). En un tramo del diálogo, la entrevistadora señala lo siguiente:

- Peguntamos a IRIS a raíz del comentario que habíamos escuchado: - ¿Schwarz quiere decir negro?

- (IRIS ) Se sonroja y con una sonrisa nos contesta: " -Si, para nosotros, los como ustedes eran todos schwarz, (negros)(...) no se decía argentinos" (ADAD: 2008, 18)

Otra vez se ha trazado una línea divisoria. Al delinear un límite, territorio del nosotros y excluyente de los otros, la que narra esta vez, posiciona a la investigadora en un espacio diferenciado y estigmatizado.

\section{A manera de cierre}

La potencialidad de trabajar con la narrativa personal reside en su posibilidad de indagar en la multiplicidad de significados -recuperar las versiones- según las cuales se dota de sentido al mundo. Se procura el reconocimiento de sí mismo y de los otros. En el espacio comunicativo de la entrevista, a través de la revisión retrospectiva de la propia vida, los que narran reconstruyen sus itinerarios y expresan sus aspiraciones, deseos, proyectos, evalúan logros y fracasos.

Los relatos de vida ponen en evidencia la trama social a través de lo particular, permiten asomarse a las modalidades en que se producen los cambios intergeneracionales, 
explorar cómo los sujetos conforman sus variadas identidades, y refieren sus adscripciones generacionales, de género, clase y étnicas. También, permiten develar capacidad de agencia de los sujetos, poniendo de manifiesto en qué medida logran apropiarse de recursos familiares y sociales, continuando con valores, modelos, mandatos, o bien los impugnan, modifican, o innovan.

La situación de encuentro, es una fuente de conocimiento útil para el investigador, -partícipe activo-, en una instancia que es oportuna para reflexionar sobre la intersubjetividad puesta en juego y las maneras en que él resulta involucrado.

* Este trabajo se realizó en el marco del Proyecto UBACYT Antropología del Presente: Prácticas profesionales, Políticas de conocimiento y Representación. Fue presentado en ocasión del III Encuentro Internacional de Historia Oral "Rescatando la memoria de nuestros pueblos", realizado en la Universidad Nacional Autónoma de Nicaragua (UNAN-Managua), del 16 al 18 de febrero del 2009.

\section{Referencias Bibliográficas}

ADAD, L. (2008) “Una auténtica alemana". Inmigración, identidad y vida cotidiana en el relato de una descendiente de colonos de alemanes del Volga. En: "El uso de la metodología biográfica en Ciencias Sociales". Seminario de Posgrado, septiembre-octubre 2007. Universidad Nacional de La Plata. Profesora: Dra. Mirta Ana Barbieri.

BARBIERI, M. (1992), “Un artista itinerante”, en Chirico Magdalena (Comp), Los relatos de vida. El retorno de lo biográfico. Los Fundamentos de las Ciencias del Hombre, $n^{\circ}$ 66, CEAL, Bs. Aires.

BARBIERI, M. (compiladora) (2000) Los relatos de vida en la investigación social, Universidad Nacional de Río Cuarto, Córdoba, Argentina.

BARBIERI, M (2008) Representaciones de lo Femenino en los Noventa. De Madres e hijas, Abuelas, Tías y Hermanas, Editorial Antropofagia, Buenos Aires.

BEHAR, R. (2006) Platícame algo aunque sea una mentira. Las historias de la comadre Esperanza, F.C.E, Méjico.

BERTAUX- WIAME, I. (1993) “The Pull of Family Ties. Intergenerational Relationships and Life Paths", en BERTAUX D. y THOMPSOM P. (editores) Between Generations Family Models, Myths and Memories, Oxford University Press, London.

BERTAUX , D, BERTAUX- WIAME, I. (1993) "El patrimonio y su linaje: transmisión y movilidad social en 5 generaciones". Estudios sobre las Culturas Contemporáneas, año/vol. VI, no 018, Universidad de Colima, México.

BERTAUX, D. (1994) “Genealogías sociales comentadas y comparadas: Una propuesta metodológica". Estudios sobre las Culturas Contemporáneas, año/vol. VI, n ${ }^{\circ}$ 16, 17 Universidad de Colima, México.

BORDERIAS, C. (1991) “Las mujeres autoras de sus trayectorias personales y familiares: a través del servicio doméstico", en Historia y Fuente Oral, nro. 6, Barcelona, España.

BOVONE, L. (1987) "Socialization and Composite Life: a Generational Ideal Type Supported by Life Stories", en Biography and Society, Italia.

BRIONES, C. (1992), "De metarelatos e identidades" en Los relatos de vida, op. cit.

GONZALEZ, J. (1995) Y todo queda entre familia. Estrategias, objeto y método para historias de familias, Estudios sobre las Culturas Contemporáneas, Vol. I. Num. 1, Universidad de Colima, México junio.

PORTELLI, A. (1992) “Narrar la historia y tiempo. Un ejemplo de Kentucky", en 
The Oral History Review, Vol.20, nros. 1 y 2, 1992. (mimeo, traducción)

PORTELLI, A. (1993) “El tiempo de mi vida: las funciones del tiempo en la historia oral", en Lozano J. (comp), Historia Oral, México, Instituto Mora, Universidad Autónoma Metropolitana.

SMOLENSKY, E. (1992), “Una mujer ítaloargentina", en Los relatos de vida, op.cit.
THOMPSOM, A. (1997), “Recompondo a memória: questo es sobre a relacao entre a história oral e as memórias". Ética e História Oral, op.cit.

THOMPSOM, P. (1993) "Family Mith, Models, and Denial", en Between Generations Family Models, Myths and Memories, Oxford University Press. 